Berkala Ilmu Perpustakaan dan Informasi, Vol. 13, No. 1, Juni 2017, Hal. 37-46 DOI: http://10.22146/bip.26086

ISSN 1693-7740 (Print), ISSN 2477-0361 (Online)

Tersedia online di https://jurnal.ugm.ac.id/bip

\title{
EVALUASI PERSIAPAN PERPUSTAKAAN STIKES 'AISYIYAH YOGYAKARTA DALAM MEMBANGUN PERPUSTAKAAN DIGITAL
}

\author{
Irkhamiyati $^{1}$ \\ ${ }^{1}$ Perpustakaan UNISA Yogyakarta \\ Email : ir.irkham@gmail.com
}

Naskah diterima: 29 September 2016, direvisi: 10 Mei 2017, disetujui: 12 Juni 2017

\begin{abstract}
ABSTRAK
Perkembangan Teknologi Informasi menjadi suatu kebutuhan untuk memenuhi tuntutan pemustaka. Salah satunya diwujudkan melalui perpustakaan digital. Penelitian ini bertujuan untuk mengetahui persiapan Perpustakaan STIKES 'Aisyiyah Yogyakarta dalam membangun perpustakaan digital, mengetahui harapan adanya perpustakaan digital dan kebijakan pimpinan, kendala, serta upaya mengatasinya. Metode yang digunakan dengan pendekatan deskriptif kualitatif. Pemilihan subjek dengan purposive sampling. Teknik pengumpulan data menggunakan observasi, in-depth inteview, dan dokumentasi. Analisis data secara interaktif dilengkapi uji keabsahan data. Evaluasi persiapan dilakukan menurut pendapat Ian H. Witten- David Bainbridge, serta Lucy A. Tedd. Hasil penelitian menunjukan sebagian besar komponen sudah dipersiapkan Perpustakaan STIKES 'Aisyiyah Yogyakarta dalam membangun perpustakaan digital, namun ada beberapa komponen yang harus dipersiapkan lagi. Kendala yang dihadapi berupa keterbatasan Sumber Daya Manusia dan waktu. Beberapa upaya sudah dan akan dilakukan untuk mengatasi kekhawatiran akan kegagalan dalam membangun perpustakaan digital. Usulan pimpinan merekrut tenaga lepas dari luar perlu dipertimbangkan perpustakaan. Penulis menyarankan agar pengelola perpustakaan terus menambah pengetahuan tentang perpustakaan digital, untuk mengatasi kendala teknis yang ada. Penambahan pakar dari luar dalam tim pengembang perpustakaan digital sebagai sarana komunikasi dan konsultasi diperlukan untuk lebih menguatkan pencapaian tujuan dibangunnya Perpustakaan Digital STIKES 'Aisyiyah Yogyakarta.
\end{abstract}

Kata Kunci: evaluasi, persiapan, perpustakaan digital, STIKES 'Aisyiyah Yogyakarta.

\section{ABSTRACT}

The development of information technology becomes necessary to serve library users, particularly to develop digital libraries. The aim of this study is to examine the preparation of the library of STIKES Aisyiyah Yogyakarta to build digital libraries, users and policy makers expectations, and ways to solve the challenges. Using qualitative descriptive approachand purposive sampling, data collection technique was conducted by using observations, in-depth inteviews, and documentations. The data was analysed by using validity of test data. Evaluation of the results was framed by the works of Ian H. Witten-David Bainbridge and Lucy A. Tedd. The results showed that most of the components were already prepared in the library of STIKES Aisyiyah Yogyakarta' $s$ in developinga digital library, however, but there were several components that need to be prepared better, such as human resources and time management. Several efforts have been and will be made to address those concerns to avoid failure to build a digital library. The idea to outsource should be considered. The addition of experts from outside of the library as part of the team are needed to further strengthen the digital library development. The author suggested that the library staff continue to increase knowledge about the digital libraries, to overcome the technical obstacles emerged.

Keywords: evaluation, preparation, digital libraries, STIKES 'Aisyiyah Yogyakarta 


\section{A. PENDAHULUAN}

Era teknologi informasi melahirkan banyak perpustakaan yang menerapkan teknologi informasi (IT) dalam kesehariannya, sehingga memunculkan istilah perpustakaan digital. Aplikasi TI di Indonesia sudah merupakan suatu kebutuhan untuk memenuhi tuntutan dalam memperoleh informasi. Hal ini mengantarkan pada tahap membangun perpustakaan digital, sehingga diperlukan persiapan dalam merancang dan membangunnya sesuai dengan kebutuhan dan kemampuannya.

Perpustakaan STIKES 'Aisyiyah Yogyakarta sudah merencanakan pembangunan perpustakaan digital. Beberapa permasalahan yang ada sebagai berikut: 1). aplikasi yang digunakan masih menjadi satu dengan Sistem Informasi Manajemen Perpustakaan, 2). bentuk yang dapat diakses belum standar; 3). belum terindeks oleh Google; 4). belum diketahui statistik penggunaanya; 5). karya digital lain seperti hasil download open journal dan e book disajikan dalam menu tersendiri dalam website perpustakaan, dan tidak banyak diketahui pemustaka; 6). masih terbatasnya server sebagai media penyimpannya; 7). belum ada kebijakan tertulis untuk perpustakaan digital; 8). keterbatasan kemampuan sumber daya manusia dan sarana pendukungnya, 9). belum terlaksananya program pembangunan perpustakaan digital dalam program kerja TA.2013/2014, dan 10). hilangnya $62,41 \%$ hard copy hasil penelitian berdasarkan laporan stock opname September 2014 (Perpustakaan STIKES 'Aisyiyah Yogyakarta, 2014).

Beberapa permasalah di atas mendorong untuk merencanakan pembangunan perpustakaan digital. Rumusan masalahnya sebagai berikut: 1). Bagaimanakah persiapan Perpustakaan STIKES 'Aisyiyah Yogyakarta dalam membangun perpustakaan digital?; 2). Bagaimanakah harapan akan perubahan adanya perpustakaan digital dan adakah kebijakan dari pimpinan; 3). Apakah kendala yang dihadapi dalam persiapan membangunan perpustakaan digital?; 4). Apakah upaya yang direncanakan untuk mengatasi kekhawatiran akan kegagalan dalam membangun perpustakaan digital oleh Perpustakaan STIKES 'Aisyiyah Yogyakarta?

\section{B. TINJAUAN PUSTAKA}

Bebeberapa hasil penelitian yang berhubungan dengan penelitian ini sebagai berikut. Pertama penelitian "Aplication of the Standard and Best Practice of DLF (Digital Library Federation) to Digitize Library Materials in the Selected Malasyian Academic Libraries" (Arianto, 2006).
Penelitian tersebut mengidentifikasi ada perpustakaan yang menggunakan standar dan praktik terbaik dalam mendigitalisasi. Standar yang digunakan adalah yang dikeluarkan oleh DLF (Digital Library Federation). Beberapa hasil penelitian di atas antara lain adalah sebagai berikut: 1). ketiga perpustakaan perguruan tinggi di Malaisyia tersebut menganggap bahwa thesis dan disertasi merupakan salah satu koleksi paling penting dalam digitalisasi koleksi perpustakaan digital; 2). subyek yang didigitalisasikan oleh ketiga perpustakaan perguruan tersebut berbeda-beda. Jumlah subyek yang didigitalisasikan sejalan dengan jumlah program studi yang ditawarkan oleh universitas masing-maisng; 3 ), terdapat persamaan dan perbedaan ketiga perpustakaan di atas dalam standar dan praktik DLF (Digital Library Federation) untuk mendigitalisasi koleksi perpustakaannya.

Penelitian kedua tentang Pengembangan Perpustakaan Digital di Perpustakaan Universitas Airlangga (Zoehdi, 2008). Hasil penelitian ini menunjukkan bahwa pengembangan perpustakaan digital di Perpustakaan Universitas Airlangga belum mencapai hasil yang maksimal, mulai dari pemahaman konsep tentang perpustakaan digital, penggunaan alat-alat yang membantu pengembangan perpustakaan digital, dan sosialisasi perpustakaan digital. Penelitian ketiga "Pengembangan Perpustakaan Digital Berbasis Senayan Library Management System (SLIMS) di Program Studi Teknologi Pendidikan FIP UNNES" (Pramudi, 2010). Konsep teori pengembangan perpustakaan digital dalam penelitian ini tidak dikupas, sebab lebih menekankan pada penerapan SLIMS Senayan sebagai bentuk aplikasi perpustakaan digital di Perpustakaan FIP UNNES. Penelitian ke empat "Implementasi Perpustaaan Digital (Studi Komparasi Antar Perpustakaan Universitas Negeri di Yogyakarta" (Nurkamilah, 2012). Hasil penelitian ini memberikan informasi bahwa terdapat perbedaan dalam implementasi Perpustaaan Digital di Perpustakaan UGM, Universitas Negeri Yogyakarta, dan UIN Sunan Kalijaga Yogyakarta, ditinjau dari aspek Sumber Daya Manusia, aplikasi yang digunakan, aksesbilitas koleksi digital, regulasi, dan kendala yang ada.

Keempat penelitian di atas mempunyai persamaan subyek tentang perpustakaan digital, namun masing-masing mempunyai titik penekanan sendiri-sendiri. Subyek spesifik penelitian ini berbeda dengan keempat penelitian di atas dan masih 
baru. Subyek dalam penelitian ini belum dikaji dalam beberapa penelitian di atas, yaitu tentang evaluasi persiapan Perpustakaan STIKES 'Aisyiyah Yogyakarta dalam membangun perpustakaan digital.

\section{Landasan Teori}

\section{Evaluasi Persiapan}

Evaluasi berasal dari kata evaluation, artinya penilaian yang dalam Bahasa Indonesia berarti menilai tetapi dilakukan dengan mengukur terlebih dahulu (Arikunto, 1997). Adapun menurut Chowdhury (2015) tujuan akhir evaluasi perpustakaan digital untuk menilai dampak perpustakaan digital pada kehidupan pelanggan dan lingkungan sosial yang lebih besar.

\section{Pengertian dan Konsep Perpustakaan Digital}

Definisi perpustakaan digital menurut pendapat Arms (2000) dalam Pendit (2007) sebagai berikut. "Sebuah koleksi yang memuat informasi yang dikelola dengan layanan untuk sekumpulan komunitas di mana informasi tersebut disimpan dalam format digital dan dapat diakses melalui jaringan. Bagian penting dari definisi ini adalah bahwa informasi tersebut dikelola".

Pengertian di atas menjelaskan bahwa sebuah informasi yang tersimpan dalam format digital, harus dapat diakses melalui jaringan. Berdasarkan pengertian di atas, penulis berpendapat bahwa perpustakaan digital selain menyediakan sumber informasi untuk kalangan sendiri, juga menyediakan sarana dan pengelolanya, sehingga sumber informasi digital tersebut dapat dimanfaatkan oleh siapa saja, yang terhubung melalui jaringan internet. Dengan demikian perpustakaan digital menyediakan akses yang cakupannya lebih luas.

\section{Tujuan Dibangunnya Perpustakaan Digital}

Beberapa tujuan dibangunnya perpustakaan digital menurut Association of Research Library (ARL) (1995) dalam Nurkamilah (2012) yaitu:

Untuk memperlancar pengembangan yang sistematis tentang cara mengumpulkan, menyimpan, dan mengorganisasi informasi dan pengetahuan dalam format digital.

1. Untuk mengembangkan transfer informasi yang hemat dan efisien di semua kalangan.

2. Untuk mendorong upaya kerja sama yang sangat mempengaruhi investasi pada sumbersumber penelitian dan jaringan komunikasi.
3. Untuk memperkuat komunikasi dan kerja sama dalam penelitian, perdagangan, pemerintah, dan lingkungan pendidikan.

4. Untuk mengadakan peran kepemimpinan internasional pada generasi berikutnya dan penyebaran pengetahuan ke dalam wilayah strategis yang penting.

5. Untuk memperbesar kesempatan belajar sepanjang hayat.

Secara lebih jelas, tujuan utama dibangunnya perpustakaan digital adalah untuk memberikan akses kepada seluruh pemakai, yang orientasi cara penyampaian dan penyebaran informasinya cepat, akurat, handal (Carpenter, 1998) dalam Zoehdi (2008). Pendapat ini sama menurut Arianto (2015) bahwa tujuan utama perpustakaan digital adalah untuk menambah koleksi, memperluas layanan, mengelola aset, menghemat tempat, memperluas akses, menyimpan/mengarsip, memudahkan pencarian, menghemat biaya, meningkatkan citra, dan preservasi. Menurut Kranich (1999) perpustakaan digital juga menawarkan keuntungan seperti akses yang adil, mengurangi hambatan jarak, ketepatan waktu, sumber daya yang dapat dimanfaatkan bersama, dan kemudahan pengiriman konten. Selain itu, perpustakaan digital menjanjikan paradigma layanan baru yang menarik di abad ke21.

\section{Sumber Informasi Digital}

Sumber informasi digital sering diartikan dengan koleksi digital atau materi digital. Koleksi digital biasa diasumsikan dengan himpunan kepemilikan yang tertata rapi. Berdasarkan sumber dan sifatnya, sumber informasi digital dikelompokkan menjadi dua jenis, yaitu born digital dan institusional repository. Born digital adalah koleksi yang lahir sudah dalam bentuk koleksi digital (Pendit , 2007). Born digital semacam ini, sering kita jumpai dalam bentuk e book, e journal, dan artikel-artikel bebas lainnya saat mendownload dari internet. Sedangkan Institusional Repository sering diartikan sebagai simpanan kelembagaan, yang merupakan hasil kaya intelektual dari lembaga atau komunitas tempat perpustakaan bernaung. Sumber informasi akan mempengaruhi model perpustakaan digital yaitu model Rolands dan Bawden, Model DELOS, dan model OAIS. 


\section{Persiapan Membangun Perpustakaan Digital}

Membangun artinya adalah memperbaiki, membina atau mendirikan (Depdiknas, 2008). Pada penelitian ini membangun diartikan sebagai proses untuk mendirikan dan memperbaiki perpustakaan digital oleh Perpustakaan STIKES 'Aisyiyah Yogyakarta. Membangun di mulai dari proses merencanakan sesuatu yang berpijak pada keadaan saat ini, yang selanjutnya akan diperbaiki dan diimplementasikan dalam pembangunan perpustakaan digital.

Ada beberapa hal yang harus disiapkan sebelum membangun perpustakaan digital. Beberapa hal tersebut disajikan dalam beberapa pertanyaannya menyangkut tiga hal pokok, yang meliputi: pengguna, wujud/materi, dan teknologi (Witten, 2010). Beberapa pertanyaan mendasar menurut pendapat Ian H.Witten and David Bainbridge sangat penting untuk mengevaluasi persiapan dalam membangun perpustakaan digital. Daftar pertanyaannya adalah sebagai berikut.

a. Pengguna: Siapakah pemustaka perpustakaan digital; Di manakah mereka berada; Bagaimanakah keterampilan komputer yang dimiliki; Bahasa apakah yang mereka kuasai; Apakah mereka akan memerlukan bantuan untuk mengakses perpustakaan; Mengapa mereka ingin mengakses sumber informasi digital; Seperti apakah teknologi yang akan digunakan; Sejauh manakah tingkat penggunaan informasi digital; Dapatkah pemustaka berkontribusi terhadap perpustakaan digital; Bagaimanakah perpustakaan akan mengevaluasi keberhasilan perpustakaan digital; dan Dapatkah pemustaka berkontribusi dalam perpustakaan digital.

b. Bahan/Materi: Apakah materi yang akan disediakan di perpustakaan digital; Apakah bentuk materi yang tersedia saat ini; Apakah bentuk yang perlu ditampilkan; Akankah pemustaka akan membutuhkan materi dengan berbagai bentuk'; Apakah bentuk materi perlu dikonversi; Bagaimanakah cara perpustakaan menyediakan peralatan konversi; Apakah materi tersebut memiliki hak cipta atau batasanbatasan lainnya; Apakah materi tersebut disediakan untuk publik atau terbatas untuk pemustaka tertentu; Apakah perpustakaan akan menambahkan nilai (misalnya metadata) untuk materi tersebut; Jika ya, bagaimanakah perpustakaan akan melakukannya. c. Teknologi: Komputer seperti apakah yang akan digunakan untuk perpustakaan digital; Siapakah yang akan merawat komputer tersebut; Apakah aplikasi yang akan digunakan; Apakah perpustakaan memiliki sumber dana u n t u k e m b e $1 \mathrm{i} / \mathrm{m}$ e $\mathrm{nd}$ a $\mathrm{pat}$ lisensi/menjalankannya; Bagaimanakah materi yang dikonversi akan ditampilkan dan diakses; Bagaimanakah perpustakaan akan mengontrol aksesnya; Bagaiman perpustakaan mengkomunikasikan sistemnya dengan perpustakaan lain; Bisakah materi digital diekspor dari soft ware perpustakaan digital; Apakah ada biaya untuk ekspor tersebut; Jika ada penambahan, apakah tambahan-tambahan tersebut dapat diekspor.

Beberapa pertanyaan dari tiga komponen di atas, akan diekstrak yang kemudian akan menjadi bahan pertanyaan yang digunakan dalam mengevaluasi persiapan Perpustakaan STIKES 'Aisyiyah Yogyakarta dalam membangun perpustakaan digital.

\section{Prinsip Membangun Perpustakaan Digital}

Ada beberapa prinsip dalam membangun perpustakaan digital. Untuk mencapai sebuah perpustakaan digital yang efektif dan efisien maka perlu mengikuti beberapa prinsip dasar sebagai berikut (Tedd, 2005): a). Mengharapkan perubahan; b). Mengetahui konten; c). Melibatkan orang yang tepat; d). Merancang sistem yang dapat digunakan; e). Memastikan akses terbuka; f). Menyadari hak kekayaan intelektual yang berkaitan dengan isi perpustakaan digital; g). Mengotomatisasi sedapat mungkin; h). Mengadopsi dan mematuhi standar; i). Memastikan kualitas;j). Kekhawatiran.

Beberapa prinsip membangun perpustakaan digital menurut Lucy A Tedd di atas, sebagian sudah tercantum dalam komponen pertanyaan untuk membangun perpustakaan digital menurut Ian H.Witten. Beberapa prinsip Lucy A Tedd yang belum tercantum dalam pendapat Ian H.Witten antara lain yaitu: harapan akan perubahan adanya perpustakaan digital dan kebijakan pimpinan, dan upaya mengatasi kekhawatiran akan kegagalan dalam membangun perpustakaan digital. Dua pendapat di atas akan ditambahkan untuk mengevaluasi persiapan Perpustakaan STIKES 'Aisyiyah Yogyakarta dalam membanguan perpustakaan digital. 


\section{METODE PENELITIAN}

Penelitian ini merupakan penelitian lapangan (field research), yang pengumpulan datanya dilakukan di lapangan untuk mengadakan pengamatan terhadap suatu fenomena dalam suatu keadaan alamiah (Susanto, 1999). Penelitian ini bersifat kualitatif, yaitu penelitian yang digunakan untuk memahami fenomena mengenai apa yang dialami subjek penelitian, seperti perilaku, persepsi, motivasi, tindakan, dll, secara holistik, dan dengan cara deskripsi dalam bentuk kata-kata dan bahasa, pada suatu konsteks khusus yang alamiah dan dengan memanfaatkan berbagai metode ilmiah (Moleong, 2008). Pendekatannya deskriptif untuk mengumpulkan informasi mengenai status suatu gejala yang lakukan, tidak dimaksudkan untuk mengukur hipotesis tertentu, tetapi hanya menggambarkan apa adanya tentang variabel, gejala, dan keadaan (Arikunto, 1998).

Penelitian ini dilakukan selama empat bulan, Februari-Mei 2015. Tempat penelitian di Perpustakaan STIKES 'Aiyiyah Yogyakarta, dengan tehnik pengambilan subjek menggunakan purposive sampling yaitu suatu tehnik yang dilandasi pada tujuan atau pertimbangan tertentu terlebih dahulu (Yusuf, 2014). Subjek dalam penelitian ini dua (2) informan yang mewakili dari jenis pemustaka perpustakaan, yang dipilih dari unsur mahasiswa dan dosen. Dua (2) informan tersebut yaitu 1 orang Kepala Bagian Perpustakaan, dan satu staf dengan job description utama pada bagian TI, satu (1) informan, yaitu Kepala Badan Pengembangan Teknologi Informasi(BPTI), dan satu orang staf BPTI yang memahami dan mendukung pembangunan perpustakaan digital, dan satu (1) informan, yaitu Wakil Ketua Bidang Akademik, selaku pimpinan yang mempunyai kewenangan dengan bidang yang diteliti. Adapun objek penelitiannya evaluasi persiapan Perpustakaan STIKES 'Aisyiyah Yogyakarta dalam membangun perpustakaan digital.

Teknik pengumpulan data menggunakan metode observasi lapangan, interview, dan dokumentasi. Metode analisis datanya secara menurut Miles dan Huberman dalam Idrus (2009), yaitu menggunakan tahap-tahap yang dimulai dari pengumpulan data, reduksi data, penyajian data, dan penarikan simpulan. Uji keabsahan data menurut Yusuf (2014), melalui uji kredibilitas, uji transferabilitas, uji dependibilitas, dan uji komformabilitas.

\section{HASIL DAN PEMBAHASAN}

\section{Pemustaka: Karakteristik, Akses, dan} Evaluasi

\section{a. Karakteristik Pemustaka Perpustakaan Digital}

Karakteristik pemustaka perpustakaan digital Perpustakaan STIKES 'Aisyiyah Yogyakarta berdasarkan wawancara mendalam terhadap para informan diketahui bahwa, pengunanya umum bisa di mana saja. Adapun keterampilan penggunaan komputer mereka minimal bisa mengoperasionalkan komputer dasar dan internet, sehingga akan mampu melakukan proses searching dan sejenisnya. Terkait dengan bahasa pemustaka, informan menyatakan bahwa sebaiknya menguasai Bahasa Indonesia dan bahasa asing, minimal Bahasa Inggris, meskipun hanya secara pasif, sehingga tidak mengalami kesulitan dalam menggunakan perpustaaan digital.

\section{a. Akses dan Kontribusi Perpustakaan Digital oleh Pemustaka}

Para informan menyatakan bahwa bantuan secara langsung kurang diperlukan, yang lebih diperlukan berupa manual/petunjuk yang ada dalam interface. Terkait dengan alasan pemustaka mengakses sumber informasi digital antara lain karena: mudah, murah, hemat, cepat, efektif, efisien, fleksibel, dan banyak hasilnya. Informan BAP (B... A... Prabowo) juga menyebutkan kelemahan perpustakaan digital, yaitu hilangnya interaksi antara pemustaka dengan pihak penyedia layanan. Adapun teknologi komputer, dan semua gadged bisa digunakan untuk mengakses perpustakaan digital. Syaratnya terhubungan dengan jaringan internet dan ada web browshernya. Uji kredibilitas dilakukan oleh peneliti dengan meningkatkan ketekunan dalam penelitian, dengan menggali informasi lebih mendalam kepada Informan IH (Ikhwan Hawariyanta). Informan IH menjelaskan bahwa teknologi yang akan digunakan meliputi server, operator, dam klien. Semua teknologi tersebut harus sesuai dengan spek masingmasing agar dapat berjalan dalam jaringan perpustakaan digital. Saat ini tingkat penggunaan informasi digital sudah lumayan tinggi, menurut informasi yang diperoleh. Selain mencari informasi, pemustaka juga bisa berkontribusi dalam perpustakaan digital. Bentuknya bermacam-macam, seperti unggah mandiri koleksinya dalam menu yang sudah disiapkan di perpustakaan digital. 


\section{b. Evaluasi Keberhasilan Perpustakaan Digital}

Hasil wawancara menunjukkan cara yang akan digunakan perpustakaan dalam mengevaluasi keberhasilan perpustakaan digital dengan cara: mencocokkan apa yang sudah ada dalam kebijakan atau proposal yang sudah disyahkan dengan hasil yang dicapai; mengecek hasil akses dengan data bibliografi perpustakaan; melihat laporan pengunjung perpustakaan digital, sehingga akan diketahui statistik pemustaka; dan melalui hasil pencarian, dan mencocokkan hasil pencarian yang sudah diiput di Sistem Informasi Manajemen Perpustakaan dengan yang di Eprints.

Informan BAP menambahkan untuk mengevaluasi keberhasilan perpustakaan digital juga bisa dilakukan dengan cara: mengecek keberhasilan penginstalan sistem yang akan digunakan dan mengecek keberfungsiannya mulai dari input data sampai proses pencarian dan download oleh pemustaka; terindeksnya data base yang ada oleh webometriks; terintegrasinya perpustakaan digital dengan perpustakaan lain dalam jaringan kerja sama.

\section{Bahan/Materi}

Wawancara mendalam dilengkapi observasi untuk mendapatkan hasil yang mendetail. Sesuai dengan teknik samplingnya yang purposive, maka wawancara kali ini hanya untuk pemustaka, pengelola perpustakaan, dan BPTI saja, yang dipandang benar-benar memahami akan hal ini. Hasil wawancara menunjukkan bahwa materi yang akan disediakan di perpustakaan digital sesuai dengan kebijakan institusi, yaitu hasil penelitian mahasiswa dan dosen (institusional repository), jurnal, buku, serta ebook yang sudah berbentuk digital (born digital). Materi yang ada saat ini berupa koleksi cetak dan digital.

Bentuk materi digital yang akan ditampilkan dalam bentuk $p d f$ dalam video (film). Konfersi ke $p d f$ diperlukan jika materinya belum dalam bentuk $p d f$ dilengkapi water mark (untuk hasil penelitian), yang bisa diakses oleh umum. Sebagian besar informan menambahkan bahwa meskipun nanti sudah terbangun perpustakaan digital, namun koleksi cetak masih tetap dibutuhkan. Kondisi demikian sesuai dengan model perpustakaan digital yang ditargetkan Perpustakaan STIKES 'Aisyiyah Yogyakarta, yaitu secara konsep, perpustakaan digitalnya sesuai dengan model Rolands and Bawden dengan terwujudnya model perpustakaan digital yang paling praktis, yaitu perpustakaan hibrida, yang masih memungkinkan perpustakaan menyediakan lokasi dan koleksi secara fisik, di samping koleksi secara digital.

Menurut pendapat para informan, koleksi harus diseleksi agar tidak melanggar hak cipta. Informan BAP mengusulkan agar ada Surat Keterangan Ketua Stikes, yang mengelola koleksi yang ada, status kepemilikan, dan keterbukaan akses , jenisnya apa saja agar perpustakaan menjadi lebih mudah dalam memanfatkan koleksi secara maksimal. Hal ini juga diperlukan jika perpustakaan harus menambahkan meta data, namun tanpa merubah isi dalam materi yang disajikan untuk pemustaka. Informan TI menjelaskan bahwa penambahan metadata lebih pada softwarenya juga, bukan dalam materi.

\section{Teknologi}

Peneliti melakukan wawancara mendalam terhadap informan. Sesuai dengan teknik purposive sampling, maka wawancara kali ini hanya untuk pengelola perpustakaan dan BPTI saja, yang benarbenar memahami hal ini. Peneliti datang ke ruang BPTI untuk mendapatkan informasi lebih jelas terkait dengan persiapan teknologi yang dipersiapakan. Evaluasi teknologi mencakup tiga hal, yaitu: komputer, konversi dan eksport data, serta cara mengontrol akses dalam perpustakaan digital.

a. Komputer yang dipersiapkan untuk membangun perpustakaan digital yaitu mencakup: komputer server dengan jaringan dan web servernya, komputer operator yang akan dijalankan oleh pustakawan, dan komputer klien.

b. Informan menjelaskan untuk merawat komputer dan data digital di perpustakaan STIKES 'Aisyiyah Yogyakarta diperlukan bentuk sinergi SDM yang akan merawat komputer dalam perpustakaan digital STIKES 'Aisyiyah Yogyakarta, yaitu yang melibatkan pengelola perpustakaan dan BPTI, dengan pembagian tugas bahwa pengelola bagian soft ware dan hard ware di komputer server dari BPTI. Sedangkan untuk komputer operator, yang bertugas merawat dari SDM perpustakaan, baik untuk merawat hard ware dan data bibliografinya.

c. Aplikasi yang akan digunakan dalam perpustakaan digital menurut penjelasan informan adalah merupakan soft ware gratis bernama Eprints versi terbaru. Alasan pemilihan soft ware ini karena memiliki 
beberapa kelebihan, seperti: jenisnya open source, sehingga gratis, terindeks dengan google, sudah bekerja sama dengan webometriks, banyak yang menggunakannya, dan komunitasnya sudah berjalan, sehingga kalau ada sesuatu yang up date akan menguntungkan, karena langsung disharekan untuk umum.

d. Para informan menyebutkan bahwa soft ware yang akan digunakan gratis karena merupakan open source. Soft ware tersebut saat ini sudah didownload tanpa biaya. Informan KN menambahkan biaya yang akan diperhitungkan nanti adalah untuk orang yang menjalankan soft ware tersebut, atau sering disebut sebagai belanja jasa di STIKES 'Aisyiyah Yogyakarta.

e. Hal-hal yang berhubungan dengan materi yang dikonversi dan eksport data mencakup tampilan format materi yang dikonversi, eksport materi ke software perpustakaan digital, biaya eksport, dan adanya tambahan yang bisa dieksport.

f. Jika ada materi yang dikonversi, maka tampilan format yang dapat diakses nantinya menurut para informan tetap berupa pdf dengan diberi water mark, dan readonly.

g. Berdasarkan hasil wawancara diketahui bahwa materi digital bisa diekspor dari software perpustakaan digital. Informasi BAP menjelaskan bahwa rencananya ada dua strategi dalam mengeksport data dari SIM Perpustakaan ke Eprints sebagai berikut.

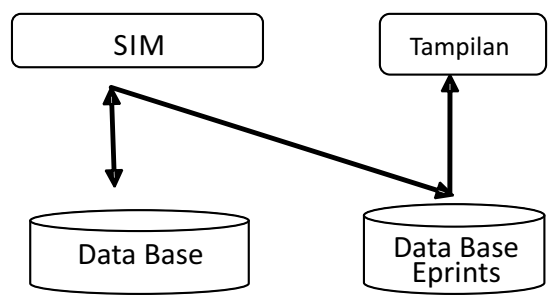

Gambar 2. Strategi 1 Eksport Data

Gambar di atas menjelaskan tentang strategi 1 yang direncanakan untuk mengeksport data dari SIM Perpustakaan ke tampilan data di Eprints, sebagai software yang dipilih untuk perpustakaan digital. Cara kerjanya yaitu data akan diinput di SIM Perpustakaan, kemudian data dan materi tersebut akan ditampilkan di SIM Perpustakaan. Selanjutnya dari tampilan dan materi tersebut akan dilinkkan/dikoneksikan ke data base Eprints, yang selanjutnya data dan materi, baru ditampilkan di tampilan Eprints.
Strategi ke dua di bawah ini berbeda dari strategi pertama, yang terlihat dalam gambar berikut.

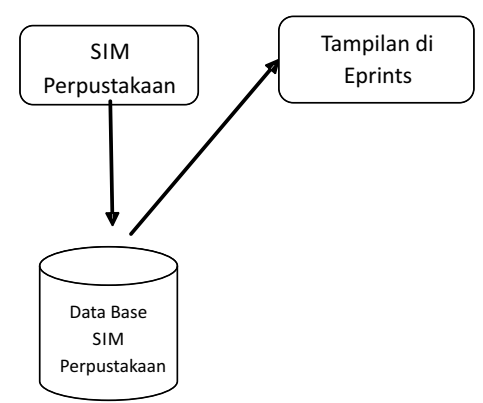

Gambar 3. Strategi 2 Eksport Data

Gambar di atas menjelaskan bahwa jika menggunakan strategi 2 , maka proses kerjanya sebagai berikut: data diinput di SIM Perpustakaan, lalu ditampilkan di SIM Perpustakaan. Data dan materi yang diinput tadi, kemudian langsung dilinkkan/upload ke dalam tampilan di Eprints.

Berdasarkan dua strategi tersebut, maka akan dipelajari dan dipilih, strategi mana yang paling efektif dan efisien untuk digunakan, sehingga mencapai hasil sesuai dengan yang sudah direncanakan sejak awal.

h. Cara yang akan dilakukan oleh Perpustakaan STIKES 'Aisyiyah Yogyakarta dalam mengontrol aksesnya nanti belum diketahui secara pasti. Dua informan menggagas cara mengontrolnya dengan menu membership untuk login anggota, namun secara lebih mendetail belum diketahui lebih mendalam.

\section{Harapan Adanya Perpustakaan Digital dan Kebijakan Pimpinan}

Peneliti melakukan wawancara mendalam terhadap semua informan, baik dari unsur pemustaka, pengelola perpustakaan, BPTI, dan pimpinan untuk mengetahui harapan dan kebijakan ini. Berdasarkan informasi di bawah ini diketahui bahwa yang menjadi harapan nanti adalah koleksi Perpustakaan STIKES akan diakses oleh siapa saja, dengan begitu akan memberi manfaat bagi pihak lain.

Pendapat senada diungkapkan oleh informan $\mathrm{KN}$, dia mengatakan nantinya akses akan lebih mudah dan luas karena terindeks juga oleh google. Hal ini semakin menunjukkan bahwa perpustakaan mampu mensuport mendukung STIKES 'Aisyiyah Yogyakarta. Salah satunya dengan menaikkan 
rangking webometriks STIKES. Sebagai timbal baliknya, harapannya perpustakaan akan lebih diperhatikan, sehingga disetujuinya tambahan SDM perpustakaan yang khusus menangani perpustakaan digital dan TI. Pendapat informan AS hampir sama dengan pendapat KN. Informan AS nemmenambahkan agar perubahan adanya perpustakaan digital nantinya bisa mengurangi adanya plagiarisme. Informan BAP menambahkan tentang harapannya selain akan membuat STIKES lebih dikenal karena banyak yang mengaksesnya, juga akan meningkatkan kesadaran pemakaian internet untuk informasi digital, tidak hanya untuk hiburan saja. Hal ini akan mengefektifkan bandwich, karena internet digunakan untuk hal-hal positif.

Terkait dengan kebijakan dari pimpinan yang mengatur tentang perpustakaan digital, diperoleh informasi bahwa kebijakan dari STIKES pasti ada sebagai pedomannya. Informan KN menambahkan bahwa kebijakan tersebut tertulis dalam sebuah proposal, yang sudah disyahkan oleh pimpinan. Komitmen dari pimpinan juga sangat tinggi akan program pembangunan perpustakaan digital ini. Buktinya pimpinan hadir dan memberikan banyak masukan serta apresiasinya dalam rapat dengan para tim, yang dilaksanakan beberapa bulan yang lalu.

Informan IM sebagai seorang pimpinan mempunyai harapan yang lebih jauh. Beliau berharap dengan perpustakaan digital nantinya bisa meningkatkan kualitas STIKES, terlebih ke depannya juga sedang proses menjadi universitas. Adanya perpustakaan digital diharapkan menjadi nilai jual tersendiri, karena bisa sebagai sebuah unggulan. Dengan demikian perpustakaan bisa mewujudkan fungsinya sebagai jantungnya perguruan tinggi. Informan IM menambahkan, kebijakan tersebut sudah ada, tapi tidak menutup kemungkinan bahwa kebijakan tersebut seiring jalannya waktu dan program perlu dievaluasi dan diperbaiki, agar lebih baik lagi.

\section{Kendala yang Dihadapi Dalam Persiapan}

Berdasarkan hasil wawancara dengan beberapa informan diketahui bahwa ada sedikit kendala yang dihadapi. Kendala utama yang dirasakan menurut informan dari perpustakaan pada SDMnya. Keterbatasan SDM membuat rasa ketergantungan pada bagian TI, sementara pekerjaan orang TI juga sangat banyak. Begitu pula dengan pengetahuan akan soft ware yang akan digunakan nantinya juga menjadi kendala dalam program ini. Adapun informan dari bagian TI mengatakan bahwa yang menjadi kendala hanya soal waktu. Informan IH menambahkan bahwa mereka butuh waktu yang cukup untuk mempelajari Eprints dan mensinkronkannya dengan SIM Perpustakaan yang ada.

Penulis melakukan uji transfermability, sebagai bentuk validitas eksternal yang menunjukkan derajat ketepatan sehingga hasil penelitian dapat diterapkan di tempat lain (Moleong, 2008). Pada penelitian kualitatif ini peneliti mencoba prinsip transfermability dengan mencocokkan kendala yang ada tersebut pada perpustakaan lain di luar partisipan. Peneliti mencocokkan dengan pengelola perpustakaan digital di Perpustakaan UIN Sunan Kalijaga Yogyakarta, dan ISI Yogyakarta. Hasilnya sama, mereka merasakan kendala tentang pengetahuan SDM dan waktu.

\section{Upaya untuk Mengatasi Kekhawatiran akan Kegagalan Membangun Perpustakaan Digital}

Solusi digunakan sebagai jalan keluar untuk mengatasi permasalahan yang ada. Informan KN memilih solusi dengan tetap mencoba apa yang sudah dilakukan oleh bagian TI, dan harus menjalin komunikasi yang baik dengan mereka agar program ini berhasil sesuai yang direncanakan.

Upaya yang dapat dilakukan menurut informan AS (Agung Suyudi), dengan menambah pengetahuan, seperti mengikuti pelatihan yang diadakan oleh FPPTI(Forum Perpustakaan Perguruan Tinggi Indonesia), sharing dengan perpustakaan lain yang sudah menggunakannya Eprints. Berdasarkan observasi yang dilakukan peneliti, diperoleh informasi tambahan bahwa sebagai upaya mengatasi hambatan akan lemahnya pengetahuan SDM terkait dengan perpustakaan digital dilakukan studi banding. Upaya yang pernah dilakukan oleh Perpustakaan STIKES 'Aisyiyah Yogyakarta untuk mengatasi hal tersebut maka dilakukan dengan cara berikut: studi banding ke perpustakaan lain, yaitu UIN Sunan Kalijaga Yogyakarta dan UGM, mengadakan seminar nasional dengan tema "perpustakaan digital dan resouches sharing", dan mengikuti pelatihan Eprints yang diadakan oleh FPPTI.

Informan BAP kembali mengatakan karena yang dianggap sebagai kendala yakni waktu, maka solusinya adalah waktu juga. Solusi yang dia sampaikan dengan menambah waktu agar lebih leluasa dalam mempelajari dan menyiapkan soft 
ware yang akan digunakan, sehingga pembangunan perpustakaan digital bisa berhasil sesuai rencana. Pernyataan informan IH senada dengan BAP di atas, selain solusinya butuh waktu yang cukup untuk mepelajari soft warenya, juga butuh kesiapan SDM dan dukungan keuangan nantinya.

Solusi yang ditawarkan oleh informan IS (Ismarwati) sebagai seorang pimpinan sedikit berbeda, yaitu: perpustakaan harus lebih mempelajari IT yang berhubungan dengan perpustakaan digital ini, sehingga sedikit mengurangi rasa ketergantungan pada orang TI. Selain itu dengan merekrut tenaga lepas dari luar, yang paham akan TI berhubungan dengan perpustakaan digital, meskipun perlu pemikiran lebih mendalam terkait dengan angggaran dana, dan sebagainya.

Penulis melakukan uji transfermability, sebagai bentuk validitas eksternal yang menunjukkan derajat ketepatan sehingga hasil penelitian dapat diterapkan di tempat lain (Moleong, 2008). Pada penelitian ini peneliti mencoba uji transfermability dengan mencocokkan upaya yang dilakukan tersebut pada perpustakaan lain di luar partisipan. Peneliti mencocokkan dengan pengelola perpustakaan digital di Perpustakaan ISI Yogyakarta, karena pada saat penelitian ini dilakukan, pengembangan perpustakaan digitalnya belum tercapai sepenuhnya. Informasi yang diperoleh hampir sama dan masih terus berupaya untuk mempelajari soft ware Eprint yang sudah terlanjur digunakan.

Penulis juga melakukan uji dependenbility terhadap hasil penelitian di atas. Dependenbiliy merupakan subtitusi istilah releabilitas dalam penelitian non kualitatif (Moleong, 2008). Dependenbility, menurut Yusuf (2014), dengan mengaudit seluruh proses penelitian, caranya dengan mengkaji ulang tahap demi tahap yang dilalui saat melaksanakan penelitian, apakah sudah sesuai dengan yang seharusnya.

Audit dilakukan oleh audit eksternal reviewer untuk meneliti kecermatan data dan dokumen yang mendukung penelitian. Eksternal reviewernya yakni dosen pembimbing yang memeriksa cara dan analisa data yang dilakukan peneliti. Analisis data telah dilakukan yang menghasilkan enam tema besar hasil penelitian. Selanjutnya peneliti siap menunjukkan bukti kerja tertulis/rekaman/dokumentasi, dan sejenisnya, yang sudah dilakukan sejak menentukan masalah, turun ke lapangan, menentukan informan/sumber data penelitian, melakukan analisis data, menguji keabsahan data, dan membuat simpulan, sebagai hasil dari uji dependenbility .
Uji confirmability juga dilakukan terhadap hasil penelitian di atas. Confirmability merupakan pemastian bahwa sesuatu itu obyektif atau tidak bergantung pada persetujuan beberapa orang terhadap pandangan, pendapat dan penemuan dalam penelitian (Moleong, 2008). Pada penelitian ini peneliti melakukan confirmability dengan cara mengumpulkan dokumentasi hasil penelitian berupa catatan lapangan dan transkrip wawancara. Hasil transkrip wawancara tersebut diberikan kepada informan untuk dilakukan analisis guna menjamin obyektifitas hasil penelitian. Setelah para informan menyetujuinya, maka dimintakan tanda tangan pada hasil transkrip wawancara tersebut.

\section{E. KESIMPULAN}

\section{Kesimpulan}

Sebagian besar komponen sudah dipersiapkan oleh Perpustakaan STIKES 'Aisyiyah Yogyakarta dalam membangun perpustakaan digital, dilihat dari unsur pemustaka, materi, dan teknologi.

a. Harapan akan perubahan adanya perpustakaan digital yaitu akses lebih mudah dan luas Kebijakan tertulis tentang perpustakaan digital STIKES 'Aisyiyah Yogyakarta tertuang dalam sebuah proposal yang sudah disyahkan, namun perlu dievaluasi dan diperbaiki, agar lebih baik lagi. Dukungan dan kKomitmen pimpinan sangat tinggi.

b. Kendala yang dihadapi dalam persiapan membangun perpustakaan yaitu keterbatasan pengetahuan SDM perpustakaan tentang soft ware yang akan digunakan, mengakibatkan rasa ketergantungan pada stafTI.

c. Kekhawatiran akan kegagalan dalam membangun perpustakaan digital di STIKES 'Aisyiyah Yogyakarta perlu dicarikan solusinya, dengan berbagai upaya.

\section{Saran}

a. Perpustakaan STIKES 'Aisyiyah Yogyakarta agar lebih memperhatikan persiapan dalam membangun perpustakaan digital pada bagianbagian yang masih lemah (SDM dan software), cara pengontrolan akses yang belum begitu dipahami, dan bentuk kontribusi pemustaka dengan cara melakukan unggah mandiri.

b. Untuk mewujudkan harapan maka Perpustakaan STIKES 'Aisyiyah Yogyakarta perlu mengevaluasi kebijakan yang sudah ada, untuk penyempurnaan lebih lanjut, guna mencapai tujuan yang sudah ditetapkan. 
c. Untuk mengatasi kendala keterbatasan SDM dan waktu, maka staf TI yang sangat padat, perlu dipertimbangkan untuk dengan melibatkan pihak luar.

d. Usul pimpinan untuk merekrut tenaga lepas dari luar dalam bidang TI perlu dipertimbangkan untuk mewujudkan target yang sudah ditetapkan.

\section{DAFTAR PUSTAKA}

Arianto, M. Solihin, 2006. Aplication of the Standard and Best Practice of DLF (Digital Library Federation) to Digitize Library materials in the Selected Malasyian Academic Libraries. Thesis. (Malasyia: International Islamic University Malaisyia.

-.......... 2015. "Membangun dan Mengembangkan Perpustakaan Digital", Makalah Seminar Nasional Perpustakaan: Digital Libary and Resource Sharing di Perpustakaan STIKES 'Aisyiyah Yogyakarta, tanggal 2 Februari 2015.

Arikunto, Suharsimi, 1998. Manajemen Penelitian. Jakarta: Rineka Cipta.

Arikunto, Suharsimi, 1997. Dasar-Dasar Evaluasi Pendidikan. Jakarta: Bumi Aksara.

Chowdhury, Sudatta, et al, 2015. "Usability and Impact of Digital Libraries: A Review. Informasi online Review Vol.30. No.6 (2006): 656-680. Emerald Grup Publishing". dalam http://bit.ly/1EuHVhb, diakses Selasa, 17 Februari 2015.

Departemen Pendidikan Nasihnal, 2008. Kamus Bahasa Indonesia. Jakarta: Pusat Bahasa Depdiknas.

Idrus, Muhammad, 2009. Metode Penelitian Ilmu Sosial: Pendekatan Kualitatif dan Kuantitatif. (Jakarta: Erlangga, 2009).

Kranich, Nancy, 1999. "Collaborating to Build a Global Digital Librar", dalam Electronic Library Vol.17. No. 6 (Desember 1999): 353 354, http://bit.ly/1xwv7So, diakses Selasa, 17 Februari 2015.
Moleong, Lexy J , 2008. Metodologi Penelitian Kualitatif. Bandung: Remaja Rosda Karya.

Nurkamilah, Siti Nur, 2012. Implementasi Perpustakaan Digital (Studi Komparasi Antar Perpustakaan Universitas Negeri di Yogyakarta). Thesis. Yogyakarta: P r o g r a m Pasca Sarjana UIN Sunan Kaliaga.

Pendit, Putu Laxman, 2007. Perpustakaan Digital: PerspektifPerpustakaan Perguruan Tinggi Indonesia. Jakarta: Sagung Seto.

Perpustakaan STIKES 'Aisyiyah Yogyakarta. Laporan Stock Opname Periode Semester Gazal TA. 2013/2014. (Yogyakarta: Perpustakaan STIKES 'Aisyiyah Yogyakarta, 2014)

Pramudi, Ery Setyo, 2010. Pengembangan Perpustakaan Digital Berbasis Senayan Library Management System (SLIMS) di Program Studi Teknologi Pendidikan FIP UNNES. Skripsi. Semarang: Universitas Semarang.

Susanto, Sahid, 1999. Manajemen Pendidikan Tinggi Berwawasan Entrepreuner. Yogyakarta: Gama Press.

Tedd, Lucy A and Andrew Large, 2005. Digital Libraries: Principles and Practice in A Global Envoronment. Munchen: K.G. Saur.

Witten, Ian $\mathrm{H}$ and David Bainbridge, 2010. How to Build a Digital Library. 2nd Ed. USA: Elsevier,.

Yusuf, A. Muri, 2014. Metode Penelitian Kuantitatif, Kualitatif, dan Penelitian Gabungan. Jakarta: Prenada Media Group.

Zoehdi, Muhammad, 2008. Pengembangan Perpustakaan Digital di Perpustakaan Universitas Airlangga. Thesis. Yogyakarta: UGM. 353-354, http://bit.ly/1xwv7So, diakses Selasa, 17 Februari 2015. 